\title{
A aquisição de encontros consonantais do inglês iniciados por /s/: estudo de caso com criança brasileira
}

\author{
Magliane De Marco \\ Universidade Católica de Pelotas
}

\section{Abstract}

Language acquisition studies have pointed the first language (L1) influence on this process. In a research with adolescents and adults, Fernandes (2001) and Silveira (2002) show that, in the acquisition process of English as foreign language (L2) by Brazilian Portuguese speakers, the L1 influences the L2 syllable structure acquisition. However, concerning to children, it seems that there is less infuence of L1 on the foreign language acquisition. Based on that, the aim of this paper is to analyze the word-initial /s/ clusters in English, as well as the possibility of syllable structure transference from first language to L2. The data is from a child that is still developing her phonological system and her age was 3:4 (years/months). She's acquiring Brazilian Portuguese as a first language and English, as a second. 
aquisição fonológica ocorre de forma gradual, do nãomarcado para o marcado, o que significa que se adquire primeiro o mais simples para depois, então, adquirir-se o mais complexo. Investigações sobre aquisição da fonologia mostram que a criança possui, inicialmente, a habilidade de produzir todos os sons da fala humana, porém, com o tempo, perde aqueles que não são produzidos em seu ambiente lingüístico (INGRAM, 1989, p. 96). O domínio da fonologia de uma língua implica a aquisição, entre outros aspectos, dos segmentos e das estruturas silábicas que constituem o sistema ao qual a criança está exposta.

Acredita-se que a criança tenha um papel ativo nesse processo de aquisição - o que significa um grau de autonomia -, procurando estabelecer hipóteses e adotando estratégias até alcançar o sistema fonológico do adulto e da comunidade na qual está inserida (MATZENAUER, 1990, p. 1). As primeiras palavras produzidas implicam já a existência de um sistema fonológico, o que não quer dizer que não haja um espaço de tempo entre o entendimento e a produção de palavras (INGRAM, 1989, p. 140). Com o desenvolvimento lingüístico da criança, esse sistema vai sofrendo alterações até chegar ao sistema alvo.

Essa autonomia evidenciada por estratégias ocorre não só na aquisição da língua materna (LM), mas também de uma língua estrangeira (LE). Dessa forma, é interessante que se pesquise a aquisição de uma LE em período em que o sistema da língua materna ainda não está plenamente dominado pela criança, a fim de se verificar, entre outros fatos, se as estratégias aplicadas na aquisição da LM também se fazem presentes no processo de aquisição da LE.

Muitas pessoas aprendem mais de uma língua; no entanto, esse processo pode se dar de várias maneiras. Uma criança pode ser 
exposta a duas ou mais línguas desde o início, por exemplo, se seus pais fazem uso de diferentes línguas. Nesse caso, deve-se, ainda, falar em 'aquisição de língua materna' - com a diferença de que não somente uma, mas duas línguas são 'maternas'. Em outras palavras, uma língua é considerada LM se nenhuma outra língua foi adquirida antes; de outra forma é considerada como língua estrangeira. Essa diferença é muito clara se a aquisição da LE começa quando a aquisição da LM já está completa, como no caso de adolescentes e adultos. Se a criança adquire somente uma língua como LM, considera-se 'aquisição monolíngue de LM'; se a criança está aprendendo duas línguas em paralelo refere-se à 'aquisição bilíngüe de LM'.

Muitas vezes, decidir entre usar o termo 'aquisição de LE' ou 'aquisição bilíngüe de LM' é uma questão de preferência pessoal. O uso mais freqüente na literatura refere-se à 'aquisição de LE' se ela começa durante ou após a idade de 3 ou 4 anos.

Depois de a sílaba ser aceita como unidade fonológica, os estudos a respeito de sua natureza e do papel desempenhado por ela na fonologia das línguas vêm crescendo cada vez mais.

São várias as teorias que abordam e buscam explicar a estrutura silábica, porém, para este trabalho, será adotado o modelo proposto por Selkirk (1982), uma vez que considera uma estrutura interna para a sílaba, possibilitando dessa forma o estudo de apenas um de seus constituintes.

A sílaba, representada pela letra grega $\sigma$, apresenta, portanto, uma estrutura interna: pode ser formada por um ataque ou onset e uma rima. A rima pode ser constituída por um núcleo e uma coda como em (1), conforme Selkirk (1982), baseando-se em propostas feitas anteriormente por Pike \& Pike (1947) e Fudge (1969).

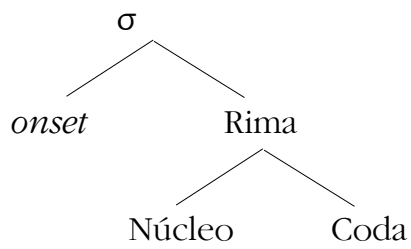


$\mathrm{Na}$ estrutura silábica do português, somente o núcleo é obrigatório, pois a língua pode apresentar sílabas com onset e/ou coda zero. O onset da primeira sílaba da palavra não pode ser constituído pelos segmentos //r/, /n/, /K//. A estrutura do onset pode possuir até duas consoantes, sendo a primeira uma plosiva ou fricativa labial, e a segunda, sempre uma líquida, como os exemplos em (2a) . O núcleo silábico no português só pode ser formado por vogais. A estrutura da coda somente aceita /N/, /S/, /1/, /r/, como se pode verificar em (2b), ou também pode apresentar duas consoantes, sendo que a segunda deve ser sempre um /S/, conforme se pode ver em (2c).

prato ['pratu]

bloco ['bloku]

(b)

(c) campo ['kampu]

sol ['sol] ['sow $]^{1}$

perspicaz [perspi'kas]

solstício [sołs'tisju] [sows't [isju] fraco ['fraku]

flor ['flor]

neste ['nest $\mathrm{i}$ i]

marca ['markə]

A inclusão de mais de um segmento na estrutura do onset, o que torna o onset ramificado, conforme podemos ver em (3), confere um grau de maior complexidade a essa estrutura. O inventário silábico do português permite um número limitado de encontros consonantais tanto em onset quanto em coda: (C) (C) V (C) (C).

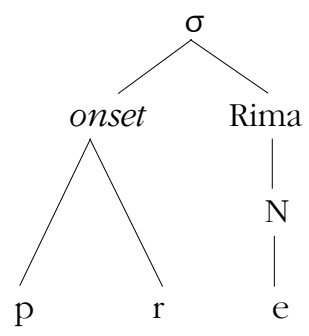

Assim como na estrutura silábica do português, no inglês, também, somente o núcleo é obrigatório, podendo apresentar sílabas com onset e/ou coda zero. 
Em inglês, a estrutura CCV apresenta dois tipos: a sílaba começa com a fricativa /s/, seguida de consoantes plosiva surdas, fricativa labial surda, nasais anteriores, líquida lateral e glides, conforme se mostra nos exemplos em (4a); ou a sílaba pode iniciar por consoantes plosivas, fricativas, africadas, nasais anteriores e líquidas seguidas de glides e líquidas, como aparece nos exemplos em (4b). A coda pode apresentar uma consoante soante ou uma obstruinte, conforme aparece exemplificado em (4c). A estrutura silábica do inglês, diferentemente do português, permite vários encontros consonantais: (C) (C) (C) V (C) (C) (C) (C).

(a)

(b)

(c)

$$
\begin{aligned}
& \text { speak ['spi:k] } \\
& \text { sleep ['sli:p] } \\
& \text { smart ['sma:rt] } \\
& \text { plum ['plım] } \\
& \text { flower ['flavər] } \\
& \text { car ['ca:r] } \\
& \text { gum ['g } \Lambda \mathrm{m} \text { ] } \\
& \text { paint ['peInt] }
\end{aligned}
$$

stool ['stu:l]
sfumato [sfu'matou]
snow ['snou]
bread ['bred]
friend ['frend]
pen ['pen]
stop ['sta:p]
clock ['kla:k]

No português, diferentemente do inglês, não há ocorrência de onset complexo que comece com /s/ no início da palavra. Portanto, determinou-se, como objeto desta pesquisa, o estudo de encontros consonantais iniciados por /s/ em início de palavra, produzidos por uma criança que está adquirindo o português como LM e o inglês como LE. Uma vez que se sabe que mesmo em palavras consideradas empréstimos, como por exemplo stress, os falantes nativos do português brasileiro tendem a produzi-la [is'tres], com um [i] epentético. Esse output é obtido porque o falante nativo do português brasileiro, ao se deparar com uma estrutura não existente em sua língua, lança mão de uma estratégia, nesse caso estratégia de epêntese, para tornar essa estrutura compatível com as estruturas de sua LM.

Os estudos sobre aquisição de língua estrangeira têm apontado a influência da língua materna nesse processo. Em uma pesquisa com adolescentes e adultos, Fernandes (2001) e Silveira (2002) mostram que, no processo de aquisição do inglês como língua estrangeira por 
falantes nativos de português, a LE sofre interferência da estrutura silábica da língua materna, já que essas duas línguas apresentam algumas estruturas silábicas diferentes. Em se tratando de crianças, porém, essa interferência da LM na aquisição da LE parece ser menor. De acordo com Fletcher e MacWhinney (1997, p.186), a criança que é exposta ainda cedo a uma segunda língua desenvolve mais precocemente uma consciência sobre a linguagem, o que pode diminuir essa influência da LM sobre uma LE em aquisição.

A consciência metalingüística é a habilidade de pensar sobre a linguagem como um objeto e desenvolve-se gradualmente durante a infância, só estando totalmente estabelecida aos oito ou nove anos de idade. As crianças pequenas, como os falantes em geral, normalmente tendem a ver a linguagem como um meio de comunicação, com ênfase principal no conteúdo e no uso e não na forma de um enunciado (FLETCHER e MACWHINNEY, 1997, p.288). Segundo Morais (1989), a consciência fonológica é uma capacidade metalingüística que se refere à representação consciente das propriedades fonológicas e das unidades constituintes da fala, ou seja, é a consciência dos sons que compõem as palavras que ouvimos e falamos (CARDOSO-MARTINS, 1991). A capacidade metafonológica pressupõe o conhecimento não do que significa uma palavra, mas de que ela é um todo formado por unidades fonológicas menores, como por exemplo fonemas e silabas. A consciência fonológica requer que a criança ignore o significado e preste atenção à estrutura da palavra (GOUGH e LARSON, 1996, p.15).

Esta pesquisa tem como objetivos, através de um estudo do processo de aquisição de inglês como LE por uma criança em etapa de desenvolvimento fonológico, verificar o processo de aquisição de encontros consonantais do inglês começados por /s/ no início de palavra e, também, verificar a existência de transferência de estruturas silábicas da LM para a LE.

Tais objetivos advêm da hipótese sobre a existência de transferência de estruturas silábicas da LM para a LE, mesmo em etapa precoce de aquisição da fonologia, e também da hipótese de que, assim como o adulto, a criança utiliza a estratégia de epêntese para reestruturar 
a sílaba ao padrão universal CV, ou a estruturas licenciadas em sua língua materna.

Para a realização da pesquisa, determinou-se um corpus constituído de dados de uma criança em desenvolvimento fonológico normal, no período em que se encontrava com idade de 3:4 (anos/ meses). A criança freqüentava escola maternal no município de Pelotas, Rio Grande do Sul, e pertence ao nível sócio-econômicocultural de classe média. Está adquirindo o português como língua materna e recebe da mãe, também nativa de Português, o input em inglês desde a idade de 2:1.

Foi analisado um corpus constituído por quarenta e cinco palavras em inglês que apresentam onset complexo iniciado por /s/ na borda esquerda da palavra. Os encontros consonantais iniciados em /s/ podem ser do tipo duplo, quando, além do /s/, apresentar mais uma consoante, ou do tipo triplo, quando for constituído por /s/ e mais duas consoantes. Os dados para esta pesquisa são constituídos por esses dois tipos de encontros consonantais. Para a coleta de dados, aplicou-se a técnica de tradução eliciada, através da qual, depois de ouvir determinada palavra em português, a criança é estimulada a produzi-la em inglês, com o objetivo de se obter uma amostra lingüística sem imitação. Algumas vezes foi necessário o uso da técnica de imitação retardada, isto é, a produção de uma palavra em uma frase, sucedida de uma série de outras palavras, e, depois, é feita a solicitação de sua realização pela criança. Para que se possa obter uma amostragem significativa, é necessário que a criança já possua um vasto vocabulário na língua estrangeira.

Todos os dados coletados foram transcritos foneticamente. Após a transcrição fonética das fitas cassetes, os dados foram analisados para obter-se a forma como essas estruturas silábicas foram produzidas pela criança.

A menina, cuja fala originou o corpus que embasa este estudo, apresentou em sua produção, com exceção de /spl/, todos os tipos de encontros consonantais iniciados por /s/ licenciados na língua inglesa, como se verifica nos exemplos em (5). 
(5)

$\begin{array}{llllll}\text { /sl/ } & \text { sleep } & \text { ['slip] } & \text { /skr/ } & \text { scream } & \text { ['skrim] } \\ \text { /sm/ } & \text { small } & \text { ['ismal] } & / \text { str/ } & \text { straw } & \text { ['stro] } \\ \text { /sn/ } & \text { snake } & \text { ['snejk] } & \text { /skw/ } & \text { squeeze } & \text { ['skwiz] } \\ \text { /sp/ } & \text { spider } & \text { ['spajdər] } & \text { /skr/ } & \text { scream } & \text { ['skrim] } \\ \text { /st/ } & \text { stool } & \text { ['stul] } & \text { /spr/ } & \text { spring } & \text { ['spring] }\end{array}$

Sabe-se que estruturas mais marcadas possuem um grau de dificuldade maior que estruturas menos marcadas, portando o onset constituído por dois elementos é mais facilmente adquirido por falantes, que o constituído por três elementos.

Pesquisas têm indicado que as duas estratégias mais utilizadas para simplificação de estruturas silábicas, presentes na LE que não seguem o padrão da sílaba da LM, são epêntese e apagamento. Para falantes nativos de inglês a estratégia de apagamento é a preferida, enquanto para os falantes nativos de português aprendendo inglês, a epêntese é mais utilizada.

A epêntese é a estratégia comprovadamente mais usada por adultos nesse tipo de onset complexo (FERNANDES, 2001 e SILVEIRA, 2002); e também foi a estratégia usada pela menina informante da presente pesquisa.

Os dados da presente pesquisa confirmam essa preferência de falantes nativos de português fazerem uso de epêntese ao utilizar inglês, pois a criança, cujos dados serviram de base para este estudo, utilizou essa estratégia para simplificar 15,55\% dos encontros consonantais iniciados por /s/ em inglês, conforme se verifica em (6). (6)

\begin{tabular}{|c|c|c|c|c|}
\hline & de $\begin{array}{l}100 \% \\
\text { epêntese } \\
(4 / 4)\end{array}$ & de $\begin{array}{l}40 \% \\
\text { epêntese } \\
(2 / 5)\end{array}$ & $\begin{array}{l}25 \% \\
\text { de epêntese } \\
(1 / 4)\end{array}$ & $\begin{array}{c}84,44 \% \\
\text { de realizações } \\
\text { apropriadas } \\
(38 / 45)\end{array}$ \\
\hline onset duplo & {$[\mathrm{sm}]$} & [sn] & & [sk, sl, sn, sp, st, str] \\
\hline onset triplo & & & {$[s t r]$} & [skr, spr, skw] \\
\hline
\end{tabular}

O que os dados em (6) estão mostrando, é que, embora a criança faça uso de epêntese, essa estratégia está preferencialmente 
sendo empregada quando o encontro consonantal é constituído de /s/ seguido de uma nasal, conforme aparece exemplificado em (7). Fica evidente também que a estrutura '/s/+nasal' está em processo de aquisição pela criança, pois, embora o encontro $/ \mathrm{sm} /$ tenha sido produzido com 100\% de epêntese, o onset formado por /sn/ obteve 60\% de suas realizações apropriadas.

$\begin{array}{llll}\text { snack } & \text { ['isnek] } & \text { small } & \text { ['ismal] } \\ \text { snake } & \text { ['isnejk] } & \text { smart } & \text { ['ismart] } \\ \text { sneaker } & \text { ['snikər] } & \text { smell } & \text { ['ismel] } \\ \text { sneeze } & \text { ['sniz] } & \text { smile } & \text { ['ismajl] } \\ \text { snow } & \text { ['snow] } & & \end{array}$

Pelos dados em (6) também pode-se observar que a menina apresenta maiores problemas no emprego de encontros consonantais iniciados por /s/ constituídos de dois elementos (83,33\% de realizações apropriadas) do que em onset complexo constituído de três elementos (88,88\% de realizações apropriadas). Diante desse resultado, tem de questionar-se a causa desse fato, que pareceria contrariar o encaminhamento de a aquisição dar-se do menos marcado para o mais marcado.

A resposta pode estar no grau de 'sonoridade' dos segmentos constitutivos dos onsets complexos do inglês. A escala de sonoridade possui um importante papel na estrutura silábica, pois relaciona a sonoridade de um segmento com a posição que ele ocupa no interior da sílaba. O elemento mais sonoro sempre ocupa o núcleo da sílaba, e os menos sonoros ocupam o onset e a coda. Quando o onset ou a coda são complexos, a sonoridade de seus segmentos é crescente em direção ao núcleo, de acordo com a escala de sonoridade, conforme apresentada em (8).

$$
\begin{aligned}
& \text { vogal }>\text { glide }>\text { líquida }>\text { nasal }>\text { fricativa }>\text { africada }>\text { plosiva } \\
& 6 \\
& 5 \\
& 4 \\
& 3 \\
& 2 \\
& 1
\end{aligned}
$$

A sonoridade do onset é sempre crescente, se se refere ao pico silábico, e a da coda, decrescente. O princípio do ciclo de sonoridade, 
segundo Clements (1990), diz que a curva de sonoridade aumenta maximamente do onset para o núcleo e cai minimamente do núcleo para a coda. Na constituição da sílaba, também há o princípio da distância de sonoridade, que trata da relação de sonoridade entre os segmentos que integram o constituinte complexo. Segundo esse princípio, para o português e espanhol, os elementos do encontro consonantal têm que ter uma distância mínima de dois pontos (HARRIS, 1983).

Empregando-se o princípio da distância de sonoridade aos encontros consonantais que fazem parte do corpus deste trabalho, obtêm-se os resultados mostrados em (9).

(9)

(a) Encontros consonantais duplos

$\begin{array}{lcccccc} & / \mathrm{sk} / & / \mathrm{s} 1 / & / \mathrm{sm} / & / \mathrm{sn} / & / \mathrm{sp} / & / \mathrm{st} / \\ \text { Valor na escala } & 20 & 24 & 23 & 23 & 20 & 20 \\ \text { Grau de distância } & 2 & 2 & 1 & 1 & 2 & 2\end{array}$

(b) Encontros consonantais triplos

$\begin{array}{lcccc} & \text { /skw/ } & \text { /skr/ } & \text { /spr/ } & \text { /str/ } \\ \text { Valor na escala } & 205 & 204 & 204 & 204 \\ \text { Grau de distância } & 25 & 24 & 24 & 24\end{array}$

Conforme podemos observar em (9a), os únicos encontros consonantais que não obedecem ao princípio da distância de Sonoridade de dois pontos entre seus constituintes - que é o grau exigido no sistema do português -, são os formados por '/s/+nasal'. Esse fato pode explicar por que esse tipo de onset é o único grupo consonantal para cuja produção a criança apresenta dificuldade.

Em todos os casos de emprego de epêntese, a informante utilizou a vogal [i] como elemento epentético. Esse fato não causa surpresa, uma vez que [i] é a vogal epentética por excelência do português. A epêntese em palavras iniciadas por /s/ resulta em sillabas do tipo VC, que, embora não constitua um universal lingüístico, é uma estrutura presente na língua materna da falante e também é uma sílaba de 
aquisição precedente, por crianças brasileiras, em se comparando com a estrutura CCV (MATZENAUER, 1990; LAMPRECHT, 1990).

No caso dos encontros formados por três consoantes, apesar de serem estruturas mais marcadas que os encontros duplos, e portanto mais difíceis de serem produzidas, já foram adquiridos pela criança. Conforme se pode ver em (6), somente o onset do tipo /str/ apresenta caso de epêntese, conforme se mostra nos exemplos em (10a). Essa estratégia somente foi utilizada quando após o encontro /str/ há a presença da vogal /i/, como aparece nos exemplos em (10b), ou seja, a mesma vogal que é utilizada como segmento epentético no português; esse núcleo silábico parece estar favorecendo a epêntese, em caso de onset constituído por três elementos.

$\begin{array}{llll}\text { (a) } & \text { /skr/ } & \text { scratch } & \text { ['skret]] } \\ & \text { /spr/ } & \text { spring } & \text { ['spring] } \\ & \text { /skw/ square } & \text { ['skwer] } \\ \text { /str/ } & \text { straw } & \text { ['stro] } \\ \text { /str/ } & \text { street } & \text { ['istrit] } \\ & & & \\ \text { (b) } & \text { /str/ } & \text { straw } & \text { ['stro] } \\ & \text { /str/ } & \text { strawberry } & \text { ['stro:bri] } \\ & \text { /str/ } & \text { street } & \text { ['istrit] } \\ \text { /str/ } & \text { strong } & \text { ['strong] }\end{array}$

Verificando-se, portanto, que o princípio de distância de Sonoridade está atuando no processo de aquisição de encontros consonantais iniciados por /s/ na informante deste trabalho, cabe-se ainda questionar por que essa aquisição está ocorrendo inicialmente com /sn/ que já apresenta 60\% de realizações adequadas, enquanto a seqüência /sm/ mostra 100\% de emprego de epêntese.

Como, nesse caso, a distância de sonoridade entre os dois segmentos do encontro é a mesma, é preciso analisar a estrutura interna de cada elemento, ou seja, os traços distintivos constituintes de cada segmento. Pode-se ver, então, que, na seqüência/sn/, os dois segmentos compartilham o ponto de articulação [coronal], enquanto na seqüência /sm/, o primeiro elemento tem o ponto [coronal] e o segundo, o ponto [labial]. 
Pelos dados em (6), a menina está adquirindo, em uma primeira etapa, os encontros com segmentos que compartilham o ponto de articulação, que é o caso de /sn/. Em uma etapa subseqüente, deverão emergir em seu sistema fonológico os encontros com segmentos que têm pontos de articulação diferenciados, que é o caso de /sm/.

Esse resultado está apontando para a ação de outro princípio, durante o processo de aquisição de encontros consonantais: o princípio de co-ocorrência de traços. Esse princípio trata de coocorrência de traços de segmentos adjacentes (esse fenômeno é conhecido na literatura como OCP - Obligatory Contour Principle).

Já foi amplamente comprovado pela literatura da área que, quanto antes uma LE for adquirida, melhor será o desempenho do aprendiz no que se refere à pronúncia. Quanto mais desenvolvido estiver o sistema fonológico da LM ao iniciar o aprendizado de uma LE, menor vai ser sua habilidade em perceber e adquirir os sons da LE (FLEGE, 1999). Pode-se concluir, então, que a criança parece perceber mais rapidamente sons que não pertencem a sua língua materna.

Pela pesquisa aqui realizada, vê-se que os dados parecem vir ao encontro da afirmação de Flege (1999) no sentido de que crianças expostas a uma segunda língua, ainda no período em que estão adquirindo a LM, apresentam produção adequada em período de tempo menor que o adulto; isto quer dizer que, quanto menor for a criança, há menos interferência da LM.

Comparando-se os dados da menina estudada neste trabalho com os dados de Silveira (2002) sobre a percepção e produção de encontros consonantais do inglês iniciados por /s/ por aprendizes brasileiros adultos, pode-se verificar que no período de 1 ano e três meses, entre 2:1 e 3:4, a criança produz 84,44\% dos encontros consonantais iniciados por /s/ de forma adequada. Pelos dados de Silveira (2002), alunos adultos brasileiros, com um ano e sete meses e 4 anos de estudo de inglês como LE, ainda apresentam dificuldade na produção de onsets iniciados por /s/, mostrando a utilização de uma vogal epentética na produção de todos os encontros iniciados por $/ \mathrm{s} /$. 
Conclui-se, portanto, que a criança ainda em fase de aquisição da fonologia parece mostrar maior facilidade e rapidez no domínio de estruturas marcadas - aqui se trata especificamente de onsets complexos constituídos por duas ou três consoantes iniciados por /s/ em início de palavra - da LE do que adultos.

A autonomia, no sentido de estabelecimento de estratégias individuais, existe na aquisição de LE, mas é regulada também pelo sistema que a criança já tem internalizado, que é o da LM. Nesse sentido, a LM, ao influenciar o processo de aquisição de uma nova língua, mostra-se como limitadora da 'autonomia' - a criança estudada não faz apagamentos (que falantes nativos de inglês fazem), faz epênteses, característica da LM.

\section{NOTAS}

${ }^{1} \mathrm{O} / \mathrm{l} /$ em coda é semivocalizado em algumas variantes lingüísticas do PB.

${ }^{2}$ Nas seqüências com encontros em que /s/ antecede uma plosiva, há a distância de dois graus de sonoridade, mas também há uma reversão de sonoridade, violando o princípio de seqüência de sonoridade (CLEMENTS, 1990, p.285) mas, segundo Clements (1990, p. 311-12), o comportamento especial das coronais anteriores não deve ter relação com a escala de sonoridade.

\section{REFERÊNCIAS BIBLIOGRÁFICAS}

CARDOSO-MARTINS, C. A sensibilidade fonológica e a aprendizagem inicial da leitura e da escrita. Cadernos de pesquisa, v. 76, p. 41-49, fev. 1991.

CLEMENTS, G. N. The role of the sonority cycle in core syllabification. In: KIGSTON, J.; BECKMAN, M. (Org.). Papers in laboratory phonology 1. Cambridge: CUP, p. 283-333, 1990.

FERNANDES P. R. C. A epêntese nas formas oral e escrita na interfonologia Português/ Inglês. In: MATZENAUER, C. L. (Org). Aquisição de lingua materna e de lingua estrangeira. Aspectos fonético-fonológicos. Pelotas: EDUCAT, 2001. p. 235-259.

FLEGE, J. Age of learning and second language speech. In: BIRDSONG, D. (Ed.). Second language acquisition and the critical period hypothesis. Mahwah: Lawrence Erlbaum Associates, 1999. 
FLETCHER, P.; MACWHINNEY, B. Compêndio da linguagem da criança. Porto Alegre: Artes Médicas, 1997.

FUDGE, E. Syllables. Journal of Linguistics, Cambridge, UK, n. 5, p. 254-287, 1969.

GOUGH, P.; LARSON, K. A estrutura da consciência fonológica. In: CARDOSOMARTINS, C. Consciência fonológica e alfabetização. Petrópolis: Vozes, 1996.

HARRIS, J. Syllable structure and stress in Spanish. A non linear analisys. Cambridge: MIT Press, 1983.

INGRAM, D. First language acquisition: method, description and explanation. USA: Cambridge, 1989.

LAMPRECHT, R. R. Perfil de aquisição normal de fonologia do português Descrição longitudinal de 12 crianças: 2:9 a 5:5. 1990. Tese (Doutorado em Letras) - Instituto de Letras e Artes, Pontifícia Universidade Católica do Rio Grande do Sul, Porto Alegre.

MATZENAUER, C. L. Aquisição da fonologia do português: estabelecimento de padrões com base em traços distintivos. 1990. Tese (Doutorado em Letras) Instituto de Letras e Artes, Pontifícia Universidade Católica do Rio Grande do Sul, Porto Alegre.

MORAIS, J. Phonological awareness: a bridge between language and literacy. In: SAWYER, D. J.; FOX, B. Phonological awareness in reading: the evolution of current perspective. Berlin: Springer, 1989.

PIKE, K.; PIKE, E. Immediate constituents of Mazateco syllables. International Journal of Applied Linguistics, n. 13, p. 78-91, 1947.

SELKIRK, E. The syllable. HULST, H. V. D., SMITH. The structure of phonological representations (part. II). Foris, Dordrecht, p. 337-383, 1982.

SILVEIRA, R. Perception and production of English initial /s/ clusters by Brazilian learners. Revista Brasileira de Lingüística Aplicada, n. 1, p. 95-119, 2002. 